\title{
Positive predictive factors and subgroup analysis of clinically relevant improvement after anterior cervical decompression and fusion for cervical disc disease: a 10- to 13-year follow-up of a prospective randomized study
}

\author{
Clinical article
}

\author{
Anna Hermansen, B.Sc., P.T., ${ }^{1}$ Rune Hedlund, Ph.D., M.D., ${ }^{2}$ \\ Ludek Vavruch, Ph.D., M.D., 3 And Anneli Peolsson, Ph.D., P.T. ${ }^{1,4}$ \\ ${ }^{1}$ Department of Medical and Health Sciences, Division of Physiotherapy, Faculty of Health Sciences, \\ Linköping University, Linköping; ${ }^{2}$ Department of Orthopaedics, Sahlgrenska University Hospital, \\ Gothenburg; ${ }^{3}$ Department of Neuro-Orthopaedic Surgery, Ryhov Hospital, Jönköping, Sweden; and ${ }^{4} C C R E$ \\ Spinal Pain, Injury and Health, Division of Physiotherapy, School of Health and Rehabilitation Sciences, \\ The University of Queensland, Brisbane, Australia
}

\begin{abstract}
Object. The main purpose of this 10- to 13-year follow-up of a prospective randomized study was to identify preoperative factors that predicted good long-term outcome after anterior cervical decompression and fusion (ACDF) with the Cloward procedure or the cervical intervertebral fusion cage. A second purpose was to investigate subgroup differences at the 10-year follow-up between patients with and without clinically relevant improvement (CRI) and between men and women.

Methods. To evaluate clinically meaningful outcomes, good outcome was defined as CRI in neck-related pain intensity ( $\geq 30$-mm improvement on a visual analog scale), and CRI in neck-specific disability ( $\geq 20 \%$ improvement in the neck disability index [NDI]) from preoperative measurements to the 10-year follow-up. A total of 73 patients (77\% of the original study sample) completed questionnaires at least 10 years after ACDF.

Results. High preoperative neck-related pain intensity and preoperative nonsmoking status were predictors of CRI in neck-related pain intensity, and male sex was a predictor of CRI in neck-specific disability; however, no additional predictive factors were identified for good outcome after ACDF. The surgical procedure, number of operated levels, and radiological factors such as healing status did not influence the prediction models. Individuals without CRI in neck-specific disability (75\%) and pain intensity (43\%) reported a worse outcome for several psychosocial outcome variables compared with those with CRI. At the 10-year follow-up, women reported significantly greater neck- and arm-related pain intensity than men, and women also reported more disability and worse psychosocial status. Women reported CRI on the NDI less frequently than men $(\mathrm{p}=0.01)$.

Conclusions. Preoperative predictive factors of good outcome 10-13 years after ACDF included initial high neck-related pain intensity, nonsmoking status at the time of surgery, and male sex. There were greater improvements in pain intensity than in neck-specific disability, and the latter showed a greater association with psychosocial factors. These results suggest the need for multimodal postoperative rehabilitation for patients who do not have a satisfactory outcome after ACDF.
\end{abstract}

(http://thejns.org/doi/abs/10.3171/2013.7.SPINE12843)

\section{KEY WoRDS - cervical disc disease - radiculopathy • anterior cervical fusion • clinical relevant outcome $\quad$ prognostic factors}

$\mathrm{M}$ ANY long-term follow-up studies show good overall outcomes for ACDF. ${ }^{11,14,30,32}$ However, other studies that include broad descriptions of

\footnotetext{
Abbreviations used in this paper: $\mathrm{ACDF}=$ anterior cervical decompression and fusion; CRI = clinically relevant improvement; $\mathrm{CSQ}=$ Coping Strategies Questionnaire; EQ-5D = EuroQol 5 dimensions instrument; NDI = neck disability index; VAS = visual analog scale.
}

patient-reported data indicate that some patients continue to experience pain and disability due to neck and/or arm symptoms after ACDF. ${ }^{23,26}$ It is important to identify factors that predict good outcome after ACDF to improve the inclusion criteria for surgery, to set patient expectations, and to improve postoperative care and rehabilita-

This article contains some figures that are displayed in color online but in black-and-white in the print edition. 


\section{A. Hermansen et al.}

tion. A number of preoperative factors of predictive importance - for good results in terms of lessening of pain intensity and good global outcome after ACDF-have been reported. These include single-level soft disc disease with short symptom duration, radicular pain, male sex, nonsmoking status, and preoperative pain and disability. ${ }^{3,9,14,19,23,24}$ Anderson et al. ${ }^{2}$ reported high preoperative NDI and employment as positive factors for successful NDI outcome. Only a few earlier studies that reported predictive factors ${ }^{2,19,23,24}$ used multivariate statistical analysis with quantification of the relative importance of each factor; of these studies, only the one by Peolsson and Peolsson ${ }^{24}$ reported follow-up longer than 2 years.

The use of CRI as an outcome measure is one way to describe a good, clinically meaningful outcome. ${ }^{31,36}$ Predictive factors of good outcome after ACDF using CRI in pain intensity as a measure are unknown, and the use of CRI in the NDI is rare. No studies have investigated subgroup differences between patients with and without CRI, and despite the finding that female sex is a predictor of poor outcome, no studies have analyzed the factors underlying the differences in outcomes between men and women. $3,9,24$

The main purpose of the present study was to identify factors that predict a good outcome 10-13 years after ACDF, with "good outcome" defined as CRI in neckrelated pain intensity and in neck-specific disability. A second purpose was to investigate subgroup differences between patients with and without CRI to analyze factors that may influence long-term outcome and to investigate differences between the sexes.

\section{Methods}

After providing informed consent, 103 consecutive patients at a university hospital in the south of Sweden (1995-1998) were randomized to treatment with either the cervical intervertebral fusion cage (AcroMed) ${ }^{33}$ or the Cloward procedure ${ }^{6}$ by an attending nurse who blindly selected a note marked either " $\mathrm{CP}$ " for the Cloward procedure or "CIFC" for the cervical intervertebral fusion cage procedure for each patient. ${ }^{33}$ The inclusion criterion was 6 months or more of radiculopathy of degenerative origin with or without neck pain. ${ }^{33}$ Exclusion criteria were myelopathy, psychiatric disorder, drug abuse, and previous spine surgery. ${ }^{33}$ All patients underwent preoperative MRI and had clinical findings of cervical nerve root compression. The randomization resulted in a similar distribution of age, sex, number of operated levels, duration of symptoms, and smoking habits in the 2 groups. Eight patients ( 3 patients randomized to the cervical intervertebral fusion cage group and 5 to the Cloward procedure group) refused surgery, leaving 95 patients in the study. ${ }^{33}$

Preoperatively and at the 1- and 2-year follow-up points after surgery, the patients underwent a standard clinical examination and radiography (anteroposterior, lateral, and oblique), and they responded to a questionnaire. ${ }^{33} \mathrm{~A}$ follow-up including additional questionnaires was performed 6 years after surgery. ${ }^{25}$ At least 10 years after surgery, a questionnaire was mailed to the remaining 90 patients who were still available for participation in the study. ${ }^{15}$ Seventy-three patients (mean age $59 \pm 8.6$ years, range 42-79 years) completed the questionnaire. Of these patients, 46 had undergone surgery at 1 level, 24 patients at 2 levels, and 3 patients at 3 levels. Seventeen patients did not complete the questionnaire despite several reminders; thus, $88 \%$ of all potential patients or $77 \%$ of those who initially underwent surgery answered the questionnaire (Fig. 1).

\section{Surgical Technique}

The Cloward procedure was performed according to standard techniques using bicortical iliac autograft harvested with the aid of a Cloward dowel cutter through a 5-cm skin incision. ${ }^{6}$ The surgical technique for the cervical intervertebral fusion cage ${ }^{33}$ is similar to the SmithRobinson technique with the addition of a carbon fiber cage to support the segment. ${ }^{29}$ No osteoinductive agents were used aside from local autologous bone graft placed in the cage. Postoperatively, all patients wore a Philadelphia collar for 6 weeks, and most of them received pragmatic physiotherapy (not designed specifically for the study) in primary care after removal of the collar.

\section{Defining Good Outcome}

A good outcome was defined as CRI (a change from preoperative values to outcome at 10-13 years of followup) in neck-related pain intensity (improvement of $\geq 30$ $\mathrm{mm}$ on a VAS) ${ }^{31}$ and in neck-specific disability (improvement of $\geq 20 \%$ on the NDI). ${ }^{10,36}$

\section{Data Included in the Prediction Models}

The following data were collected at the time of surgery: age, sex, surgery-related factors (surgical technique and number of operated levels), ${ }^{33}$ general neck-related pain intensity (in mm on a VAS) and neck-specific disability (rated using the NDI). ${ }^{33}$ Radiological factors (healing status, segmental height in $\mathrm{mm}$, and angle of segmental lordosis/kyphosis) ${ }^{33}$ were obtained preoperatively and at the 1- and 2-year follow-up time points. ${ }^{33}$

The outcome variables included in the prediction models were CRI in neck-related pain intensity and in NDI.

\section{Measures Included in the Subgroup Analyses}

Additional Surgery. The number of additional surgeries was registered from the time of surgery until the 10-year follow-up. ${ }^{15}$

Pain and Numbness. Current pain intensity ("right now") was rated on a horizontal $100-$ mm VAS $^{28}$ for neck pain, arm pain, and headache. The distribution of pain was categorized using a 7-point scale (0 [no symptoms] to 6 [most distal]) using pain drawings. ${ }^{35}$ The occurrence of neck problems during the last 6 months (yes/no) was registered. The frequency of neck and arm pain, headache, and numbness and weakness in the hand were rated using a 5 -point scale (1 [never] to 5 [constant]).

Disability. Neck-specific disability was rated using the NDI ( $0 \%$ [no disability] to $100 \%$ [maximum disabili- 


\section{Clinically relevant improvement after ACDF}

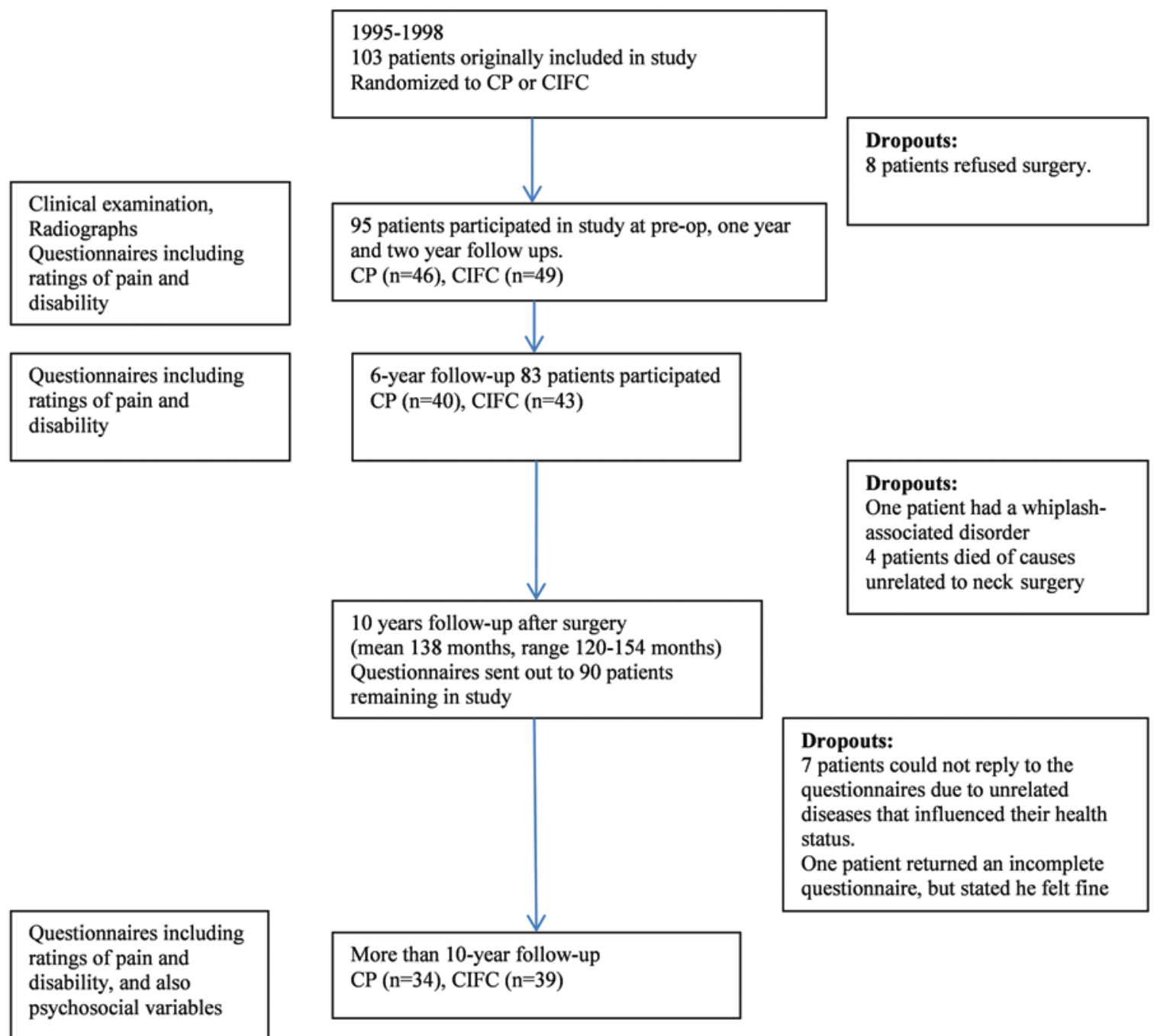

FIG. 1. Flowchart of the inclusion process. CIFC = cervical intervertebral fusion cage; $\mathrm{CP}=$ Cloward procedure.

ty]). ${ }^{34}$ The impact of neck symptoms on daily life was rated on a 6-point scale (1 [not at all] to 6 [extremely high]).

Self-Efficacy and Coping. The self-efficacy scale se $^{1,8}$ was used to investigate how confident the patient was regarding his/her ability to successfully perform certain activities despite pain. ${ }^{1}$ Cognitive and behavioral strategies influencing pain were recorded using the CSQ. ${ }^{17,27}$ The CSQ also includes 2 ratings of pain control that indicate how much control the patient has over pain and how able the patient is to decrease pain (7-point scale: $0=$ [no control] to 6 [complete control]).17,27

General Health and Global Outcome. Health-related quality of life was assessed using the EQ-5D. ${ }^{4}$ The scores on the EQ-5D were converted to an index score between 0 (poor overall health) and 1 (good overall health). Current health status was rated on the EuroQol vertical VAS $(0=$ worst imaginable, $100=$ best imaginable $) .{ }^{4}$ The patient-reported global outcome of surgery was scored on a 6-point scale (modified Odom criteria: 1 [complete relief of problems] to 6 [much worse]). The patient's experience of whether the expectations of surgery were fulfilled was scored on a 3-grade scale (1 [yes, completely]; 2 [yes, partially]; and 3 [no, not at all]).

\section{Statistical Analysis}

Background data and preoperative and surgery-related factors that might be important for a good long-term (10-year) outcome were analyzed using logistic regression due to the binary outcome of interest (presence or absence of CRI in VAS scores and NDI). The results from the predictor analysis were presented as the coefficient of determination, Nagelkerke (pseudo R-squared), and as probabilities (odds ratio).

Comparisons between subgroups were performed using the chi-square test for categorical data and the 2-tailed Student t-test or the Mann-Whitney U-test for interval and ordinal data.

Of the included 73 participants, 72 individuals had preoperative and follow-up values that were valid for calculating CRI in neck-related pain and NDI and were included in regression analysis. In the subgroup analysis, the internal missing values varied from 0 to 10 . A $\mathrm{p}$ value 


\section{A. Hermansen et al.}

$\leq 0.05$ was considered statistically significant. The descriptive statistics and comparisons of 10-year outcomes between the Cloward procedure and the cervical intervertebral fusion cage technique were reported previously by Hermansen et al..$^{15}$

\section{Results}

\section{Preoperative Predictive Factors of the 10-Year Outcome}

The initial comparisons showed higher initial (preoperative) neck-related pain intensity for women, leading to a final prediction model for CRI in neck-related pain intensity that was adjusted for sex. Preoperative factors with predictive importance for CRI in neck-related pain intensity at the 10-year follow-up were initial high neckrelated pain intensity $(\mathrm{p}=0.002)$ and nonsmoking status $(\mathrm{p}=0.05)$ (Table 1). For each millimeter increase in the preoperative VAS score for neck-related pain intensity, there was a $6 \%$ higher odds of CRI in pain intensity at the 10-year follow-up. Nonsmokers were 3 times more likely to have CRI in pain intensity than smokers (Table 1). Male sex was the only predictive preoperative factor for CRI in neck-specific disability as rated on the NDI (OR 4.33) (Table 1).

Surgery-related factors (surgical technique and number of operated levels), radiological factors (segmental height in $\mathrm{mm}$ and angle of segmental lordosis/kyphosis), duration of pain before surgery, preoperative pain drawings, and preoperative NDIs were all nonsignificant in terms of predicting a good outcome and thus did not appear in the logistic regression models. None of these parameters appeared in either model or in alternative models that included the following postoperative radiological factors: healing status, segmental height, and development of kyphosis.

\section{Subgroup Analysis at the 10-Year Follow-Up}

CRI in Neck-Related Pain Intensity and Neck-Specific Disability. A total of $57 \%$ of the patients had CRI in neck-related pain intensity and 25\% had CRI in neckspecific disability (Table 2). Patients with CRI in neckrelated pain intensity and NDI had lower scores on pain variables and NDI at the 10-year follow-up and had better global outcome scores (modified Odom criteria), selfefficacy scale scores, and general health, and they expe- rienced fewer neurological symptoms (Table 3). Patients with CRI in their NDI also scored significantly lower with regard to catastrophizing and experienced more control over their pain (Table 3). There were no significant differences in background variables (age, preoperative values of neck-related pain intensity and disability, number of operated levels, surgical technique, or radiological variables) between individuals with and without $C R I$ in pain intensity rating and/or NDI, except for preoperative values of neck-related pain intensity between CRI pain or $\operatorname{not}(\mathrm{p}=0.003)$.

Sex Differences. There were no sex differences regarding CRI in pain intensity $(\mathrm{p}=0.55)$, but significantly fewer women than men reported CRI on the NDI ( $p=$ 0.01) (Table 2).

Women reported more intense neck $(\mathrm{p}=0.009)$ and $\operatorname{arm}(\mathrm{p}=0.004)$ pain and had higher NDI values $(\mathrm{p}=$ $0.007)$. Women also had significantly higher scores in the following coping strategies (subscales of the CSQ): diverting attention, praying/hoping, catastrophizing, increased behavioral activity, and they also experienced lower self-efficacy at the 10-year follow-up (Table 3). Women reported higher preoperative pain intensity on a VAS $(p=0.01)$ than men, but the preoperative NDIs were similar $(\mathrm{p}=0.15)$.

\section{Discussion}

This study identified the following 3 preoperative variables as significant predictors of successful long-term outcome 10-13 years after ACDF: high preoperative neckrelated pain intensity, nonsmoking status at the time of the surgery, and male sex. High preoperative neck-related pain intensity and smoking explained $29 \%$ of the variability in the CRI in neck-related pain intensity. Patient sex explained $14 \%$ of the variability in CRI in NDI. The relatively low coefficient of determination (Nagelkerke R-squared) suggests that other factors that were not included in the present study may be important predictors of outcome. Such factors might include, for example, depressive symptoms and social support. Considering this, the predictive models can be viewed as fairly good.

High preoperative pain intensity was a predictor of CRI in pain intensity in the present study, in agreement with a 6 -month follow-up study by Lied et al. that used decreased pain (greater than or equal to a 2-point decrease)

TABLE 1: Predictive factors for good long-term outcome after ACDF

\begin{tabular}{lclccc}
\hline \multicolumn{1}{c}{ Parameter } & $\begin{array}{c}\text { No. of } \\
\text { Patients }\end{array}$ & \multicolumn{1}{c}{ Predictor } & Nagelkerke R & p Value & OR (95\% Cl) \\
\hline $\begin{array}{l}\text { CRI in neck-related pain } \\
\text { intensity }\end{array}$ & 71 & high preop neck-related pain intensity & $0.29^{*}$ & 0.002 & $1.06(1.02-1.10)$ \\
& & & & 0.05 & $3.03(1.00-9.12)$ \\
CRI in NDI & 72 & $\begin{array}{l}\text { nonsmoking status } \\
\text { male sex }\end{array}$ & 0.14 & 0.01 & $4.33(1.29-14.59)$ \\
\hline
\end{tabular}

* Nagelkerke R-square 0.29 is the value for the model CRI pain intensity, including all variables.

$\dagger$ At least a $30-\mathrm{mm}$ improvement in rating of neck-related pain intensity from preoperative ratings to the 10-year follow-up using a $100-\mathrm{mm}$ VAS.

$\ddagger$ At least $20 \%$ improvement in the NDI rating from preoperative ratings to 10 -year follow-up. 


\section{Clinically relevant improvement after ACDF}

TABLE 2: Individuals with a clinically relevant improvement in neck-related pain and disability*

\begin{tabular}{|c|c|c|c|c|c|}
\hline \multirow[b]{2}{*}{ Parameter } & \multicolumn{5}{|c|}{ No. of Patients (\%) } \\
\hline & Total $(n=72)$ & $\mathrm{CP}(\mathrm{n}=34)$ & $\operatorname{CIFC}(n=38)$ & Men $(n=33)$ & Women $(n=39)$ \\
\hline CRI in pain intensity $\dagger$ & $41(57)$ & $18(53)$ & $23(61)$ & $18(55 \%)$ & $23(59)$ \\
\hline CRI in NDI & $18(25)$ & $9(26)$ & $9(24)$ & $13(39 \%)$ & $5(13) \S$ \\
\hline
\end{tabular}

as the outcome measure..$^{19}$ An earlier study that was a 6-year follow-up of the same patient group as evaluated in the present study showed that low preoperative neckrelated pain intensity was a significant predictor of a good outcome as defined by pain intensity and neck-specific disability ratings (used as continuous variables), but the study did not take into account the clinical relevance of the outcome. ${ }^{24}$ The differences in results between the 6and 10-year follow-up points are most likely methodological. A low pain rating preoperatively correlates to a low rating at follow-up, whereas a high rating preoperatively is more likely to predict a clinically relevant change in score. Somewhat in contrast to the present study, Anderson et al. ${ }^{2}$ discovered that higher preoperative disability levels were a positive predictor for successful improvement in NDI (defined as a > 15-point improvement). ${ }^{2}$

Our finding that male sex and nonsmoking status were predictors of a good outcome in NDI and pain intensity, respectively, is consistent with earlier findings, $, 923,24$ indicating stability in these predictors regardless of follow-up time, method of statistical analysis, or choice of outcome variable for pain intensity. Smoking is not only a predictor of a bad outcome after $\mathrm{ACDF}^{24}$ but is also a risk factor for lumbar disc disease. ${ }^{20}$ In addition to the directly negative biological effects of cigarette smoking, one could speculate that other lifestyle and socioeconomic factors related to the habit of smoking might also be associated with surgical outcome.

Male sex as a positive predictive factor for a good outcome in terms of neck-specific disability may be explained by the observation that men have better neck muscle endurance $^{22}$ and by the tendency for less widespread pain in men; ${ }^{24}$ however, other biological, psychological, and social factors may also be involved. In the present study, women scored worse on several measures of pain, disability, and psychosocial outcomes at the 10-year or longer follow-up. Preoperatively, there were no sex differences in neck-specific disability, but unfortunately we have no information regarding patients' psychosocial status before surgery, and this could be an important factor that affects outcome? There is a need for more sex-sensitive research to improve the outcomes in women after ACDF.

In contrast to previous studies that analyzed predictive factors of successful outcome after surgery, single-level surgery and age did not influence the predictive models in the present study. Radiological factors, such as healed fusion, did not influence the predictive models. Previous studies of this sample of patients showed a notable but not significant difference in pain ratings and no difference in NDI at 2-year follow-up between individuals who presented with a fusion or pseudarthrosis. ${ }^{33}$ At the 10-year followup, when subgrouping individuals according to their 2-year healing status and evaluating outcome as continuous variables, there were significant differences in pain and NDI. ${ }^{15}$ Thus, among patients in the present study, fusion did seem to matter at the 10-year follow-up, although it was not demonstrated in the present report, possibly reflecting the fact that CRI was used as outcome. This again shows the multifactorial nature of outcome in spinal disorders. Fusion does seem to matter, but the data are obscured by multiple other variables. ${ }^{15}$ The lack of strong predictive factors besides the variables identified previously (pain intensity, nonsmoking status, and male sex) may indicate that other psychosocial factors are important at long-term follow-up, as in the present study.

The subgroup analysis showed that patients who had CRI in pain and disability ratings experienced better general health than those without CRI. Interestingly, CRI in NDI but not in pain intensity was related to a high ability to control and decrease pain and also to low levels of catastrophizing. Earlier studies showed that selfefficacy and coping strategies are important variables for surgical outcome for other orthopedic conditions, ${ }^{7,18}$ and catastrophizing has been proposed to be associated with disabling pain. ${ }^{21}$ The findings of the subgroup analysis, together with the sex differences we found regarding CRI in NDI, indicate that psychosocial factors could affect the outcome of neck-specific disability more than the pain intensity outcome.

Just over half of the patients had CRI in pain intensity at the 10-year follow-up, but fewer than one-third had CRI on the NDI. As previously reported, there was a significant reduction in long-term neck-related pain intensity and NDI from preoperative values (except for NDI in the Cloward procedure group). ${ }^{15}$ However, when classifying the individuals according to a clinically relevant improvement, far from all individuals had such a change. The reasons for this may be multifactorial, and evaluating these factors lies outside of the scope of this study. About $80 \%$ of the participants reported good global outcome (better, much better, and complete relief on modified Odom criteria) in both treatment groups..$^{15}$ In the subgroup analysis, global outcome ratings were also significantly higher in patients with a good outcome regard- 
A. Hermansen et al.

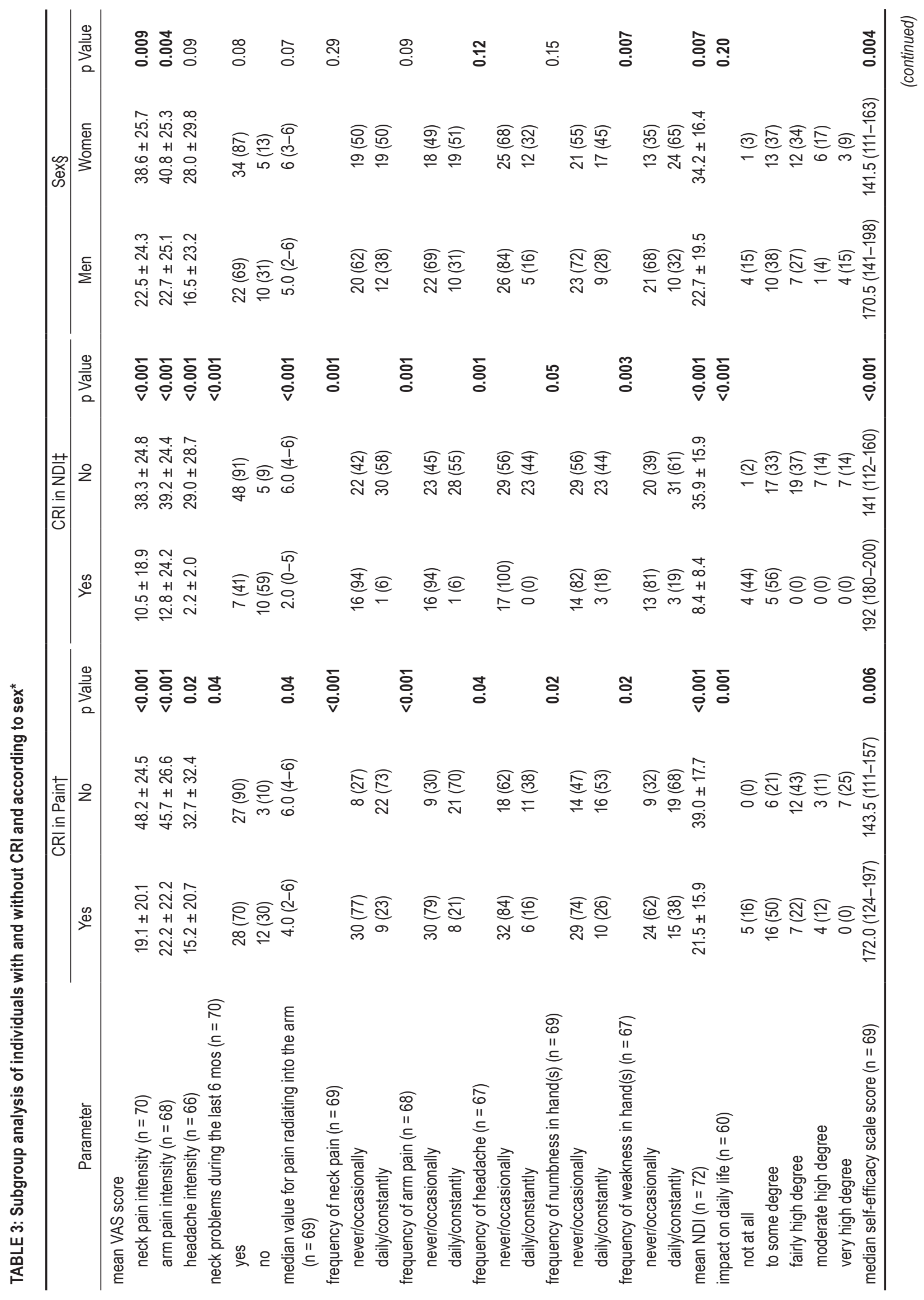




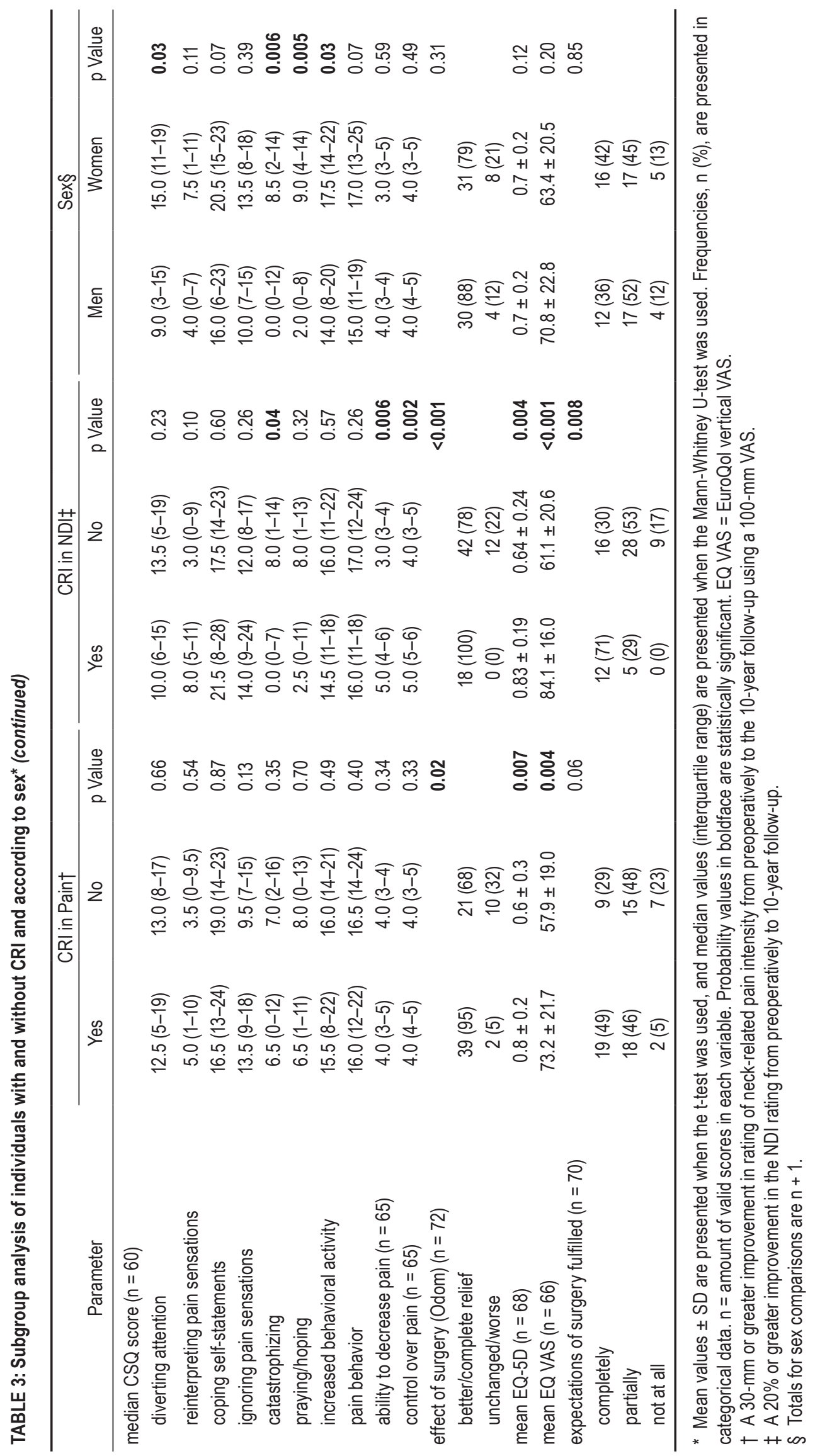




\section{A. Hermansen et al.}

ing both neck-related pain and disability (Table 3). Using CRI in pain and neck-specific disability is one method to evaluate patient-centered outcome, and global outcome ratings such as the modified Odom criteria used in the present study is another. One could speculate regarding the reasons for the discrepancy in these outcomes in the present study. First, the global outcome rating is a retrospective measure to some extent because the responder needs to recall the problems he or she experienced before treatment and compare them with the present. More than 10 years may be too long to reliably recall these experiences, and the global outcome ratings may be a measure of satisfaction with surgery and the health care system. Javid et al. ${ }^{16}$ also reported that global outcome ratings after a Cloward procedure can overestimate positive results. Specific questions regarding symptoms may be better suited for determining the extent to which the patients' problems are resolved by surgery, and accurate evaluation of the surgical outcome requires a variety of outcome measures. Long-term outcome studies of course do not only reflect the treatment given a decade earlier, but they are influenced by multiple factors affecting the individual during the time to follow-up, thereby obscuring treatment effects. Notwithstanding this, the results of the present study still add to previous knowledge, showing that patients with no CRI are different from those with a CRI in pain and disability outcomes in terms of pain, disability, and global health variables as well as psychosocial factors such as self-efficacy and catastrophizing.

Different methods can be used to define a meaningful change in outcome after intervention. These methods include effect size, minimal clinically important difference, and so forth. The high rate of patients not reporting a CRI in the present study may reflect the relatively high cutoff level for defining CRI in pain and disability. The concept of a minimum clinically important difference is, however, highly controversial and today is questioned by many authors. ${ }^{5,12,13}$ Nonetheless, the findings of high scores of remaining pain and disability in individuals without a CRI and also in women still seem to be valid ones. This study used common cutoff points for clinically relevant changes. ${ }^{10,31,36}$ Unfortunately, self-efficacy, coping strategies, and depression were not assessed preoperatively in this study. The results of the present study suggest that it is important to include such factors in future prognostic studies.

\section{Conclusions}

The variables identified as predictive factors for a good outcome in pain intensity and neck-specific disability 10-13 years after ACDF were high initial pain intensity, nonsmoking status, and male sex. A large percentage of the included patients did not report CRI in neck-specific disability (75\%) and pain intensity (43\%) at the long-term follow-up. Disability improved less and was more influenced by psychosocial factors than was pain intensity. Women had worse outcomes and were more influenced by psychosocial factors. These results suggest the need for multimodal postoperative rehabilitation for those patients who do not have a satisfactory outcome after ACDF.

\section{Disclosure}

This study has received financial support from the Swedish Research Council, the Medical Research Council of Southeast Sweden (FORSS), and also from the County Council of Östergötland.

Author contributions to the study and manuscript preparation include the following. Conception and design: Hermansen, Peolsson. Acquisition of data: all authors. Analysis and interpretation of data: Hermansen, Peolsson. Drafting the article: Hermansen. Critically revising the article: all authors. Reviewed submitted version of manuscript: all authors. Approved the final version of the manuscript on behalf of all authors: Hermansen. Statistical analysis: Hermansen, Peolsson. Study supervision: Peolsson. Recruiting patients: Hedlund, Vavruch.

\section{References}

1. Altmaier EM, Russell DW, Kao CF, Lehmann TR, Weinstein JN: Role of self-efficacy in rehabilitation outcome among chronic low back pain patients. J Couns Psychol 40:335-339, 1993

2. Anderson PA, Subach BR, Riew KD: Predictors of outcome after anterior cervical discectomy and fusion: a multivariate analysis. Spine (Phila Pa 1976) 34:161-166, 2009

3. Bertalanffy H, Eggert HR: Clinical long-term results of anterior discectomy without fusion for treatment of cervical radiculopathy and myelopathy. A follow-up of 164 cases. Acta Neurochir (Wien) 90:127-135, 1988

4. Brooks R: EuroQol: the current state of play. Health Policy 37:53-72, 1996

5. Carragee EJ: The rise and fall of the "minimum clinically important difference." Spine J 10:283-284, 2010

6. Cloward RB: The anterior approach for removal of ruptured cervical disks. J Neurosurg 15:602-617, 1958

7. den Boer JJ, Oostendorp RA, Beems T, Munneke M, Evers AW: Continued disability and pain after lumbar disc surgery: the role of cognitive-behavioral factors. Pain 123:45-52, 2006

8. Denison E, Asenlöf P, Lindberg P: Self-efficacy, fear avoidance, and pain intensity as predictors of disability in subacute and chronic musculoskeletal pain patients in primary health care. Pain 111:245-252, 2004

9. Eriksen EF, Buhl M, Fode K, Klaerke A, Krøyer L, Lindeberg $\mathrm{H}$, et al: Treatment of cervical disc disease using Cloward's technique. The prognostic value of clinical preoperative data in 1,106 patients. Acta Neurochir (Wien) 70:181-197, 1984

10. Fairbank JC, Couper J, Davies JB, O'Brien JP: The Oswestry low back pain disability questionnaire. Physiotherapy 66: 271-273, 1980

11. Faldini C, Leonetti D, Nanni M, Di Martino A, Denaro L, Denaro V, et al: Cervical disc herniation and cervical spondylosis surgically treated by Cloward procedure: a 10 -year-minimum follow-up study. J Orthop Traumatol 11:99-103, 2010

12. Ferreira ML, Herbert RD, Ferreira PH, Latimer J, Ostelo RW, Nascimento DP, et al: A critical review of methods used to determine the smallest worthwhile effect of interventions for low back pain. J Clin Epidemiol 65:253-261, 2012

13. Gatchel RJ, Mayer TG, Chou R: What does/should the minimum clinically important difference measure? A reconsideration of its clinical value in evaluating efficacy of lumbar fusion surgery. Clin J Pain 28:387-397, 2012

14. Hamburger C, Festenberg FV, Uhl E: Ventral discectomy with pmma interbody fusion for cervical disc disease: long-term results in 249 patients. Spine (Phila Pa 1976) 26:249-255, 2001

15. Hermansen A, Hedlund R, Vavruch L, Peolsson A: A comparison between the carbon fiber cage and the cloward procedure in cervical spine surgery: a ten- to thirteen-year followup of a prospective randomized study. Spine (Phila Pa 1976) 36:919-925, 2011

16. Javid D, Hedlund R, Vavruch L, Leszniewski W: Is the efficacy 


\section{Clinically relevant improvement after ACDF}

of the Cloward procedure overestimated? Technique of evaluation affects the outcome. Eur Spine J 10:222-227, 2001

17. Jensen IB, Linton SJ: Coping Strategies Questionnaire (CSQ): reliability of the Swedish version of the CSQ. Scand J Behav Ther 22:139-145, 1993

18. Keefe FJ, Caldwell DS, Martinez S, Nunley J, Beckham J, Williams DA: Analyzing pain in rheumatoid arthritis patients. Pain coping strategies in patients who have had knee replacement surgery. Pain 46:153-160, 1991

19. Lied B, Roenning PA, Sundseth J, Helseth E: Anterior cervical discectomy with fusion in patients with cervical disc degeneration: a prospective outcome study of 258 patients (181 fused with autologous bone graft and 77 fused with a PEEK cage). BMC Surg 10:10, 2010

20. Mattila VM, Saarni L, Parkkari J, Koivusilta L, Rimpelä A: Early risk factors for lumbar discectomy: an 11-year follow-up of 57,408 adolescents. Eur Spine J 17:1317-1323, 2008

21. Mercado AC, Carroll LJ, Cassidy JD, Côté P: Passive coping is a risk factor for disabling neck or low back pain. Pain 117:51-57, 2005

22. Peolsson A, Almkvist C, Dahlberg C, Lindqvist S, Pettersson S: Age- and sex-specific reference values of a test of neck muscle endurance. J Manipulative Physiol Ther 30:171-177, 2007

23. Peolsson A, Hedlund R, Vavruch L, Oberg B: Predictive factors for the outcome of anterior cervical decompression and fusion. Eur Spine J 12:274-280, 2003

24. Peolsson A, Peolsson M: Predictive factors for long-term outcome of anterior cervical decompression and fusion: a multivariate data analysis. Eur Spine J 17:406-414, 2008

25. Peolsson A, Vavruch L, Hedlund R: Long-term randomised comparison between a carbon fibre cage and the Cloward procedure in the cervical spine. Eur Spine J 16:173-178, 2007

26. Peolsson A, Vavruch L, Öberg B: Disability after anterior decompression and fusion for cervical disc disease. Adv Physiother 4:111-124, 2002

27. Rosenstiel AK, Keefe FJ: The use of coping strategies in chronic low back pain patients: relationship to patient characteristics and current adjustment. Pain 17:33-44, 1983

28. Scott J, Huskisson EC: Graphic representation of pain. Pain 2:175-184, 1976

29. Smith GW, Robinson RA: The treatment of certain cervicalspine disorders by anterior removal of the intervertebral disc and interbody fusion. J Bone Joint Surg Am 40-A:607-624, 1958

30. Sugawara T, Itoh Y, Hirano Y, Higashiyama N, Mizoi K: Long term outcome and adjacent disc degeneration after anterior cervical discectomy and fusion with titanium cylindrical cages. Acta Neurochir (Wien) 151:303-309, 2009

31. ten Klooster PM, Drossaers-Bakker KW, Taal E, van de Laar MA: Patient-perceived satisfactory improvement (PPSI): interpreting meaningful change in pain from the patient's perspective. Pain 121:151-157, 2006

32. Thorell W, Cooper J, Hellbusch L, Leibrock L: The long-term clinical outcome of patients undergoing anterior cervical discectomy with and without intervertebral bone graft placement. Neurosurgery 43:268-274, 1998

33. Vavruch L, Hedlund R, Javid D, Leszniewski W, Shalabi A: A prospective randomized comparison between the cloward procedure and a carbon fiber cage in the cervical spine: a clinical and radiologic study. Spine (Phila Pa 1976) 27:16941701,2002

34. Vernon H, Mior S: The Neck Disability Index: a study of reliability and validity. J Manipulative Physiol Ther 14:409415, 1991

35. Werneke M, Hart DL, Cook D: A descriptive study of the centralization phenomenon. A prospective analysis. Spine (Phila Pa 1976) 24:676-683, 1999

36. Young BA, Walker MJ, Strunce JB, Boyles RE, Whitman JM, Childs JD: Responsiveness of the Neck Disability Index in patients with mechanical neck disorders. Spine J 9:802-808, 2009

Manuscript submitted September 10, 2012.

Accepted July 2, 2013.

Portions of this work were presented in poster form at the 14th European Congress of Neurosurgery, The European Association of Neurosurgical Societies, Rome, Italy, October 9-14, 2011.

Please include this information when citing this paper: published online August 2, 2013; DOI: 10.3171/2013.7.SPINE12843.

Address correspondence to: Anna Hermansen, B.Sc., P.T., Department of Medical and Health Sciences, Division of Physiotherapy, Faculty of Health Sciences, Linköping University, SE-58183 Linköping, Sweden. email: anna.hermansen@gmail.com. 